\title{
Mentalidade de dieta, controle social do corpo e clínica contemporânea ${ }^{138}$
}

\section{Luciana E. Saddi 139}

As ideias que vou apresentar são fruto de duas preocupações que me levaram ao mestrado na PUC apresentado em 2007. Vou resumir alguns dos meus achados ao longo de minha investigação que já dura 20 anos.

1- Como foi que comer se transformou num enorme problema social, fruto de preocupação, medo e angústia - ampliando o número de pacientes com problemas alimentares e insatisfações com o corpo.

2- Como tratar em psicanálise esses pacientes.

Resumo de alguns dos achados ao longo de investigação que já dura 20 anos.

\section{1a Breve descrição da história da alimentação e dos cuidados com o corpo}

Segundo Foucault (1984/2006) a dietética na Antiguidade problematizava tanto a prática sexual como a ingestão alimentar. Mas o regime não fixava quantidades. Negocia caracteres globais, procurava melhorar a vida e o desempenho da sexualidade, sem propor contornar a fatalidade. Era uma espécie de recomendação do bem-viver, da arte de viver; jamais se pretendia como obediência ao saber de outro. Prática de reflexão sobre si e sobre o próprio corpo. $\mathrm{O}$ ato sexual não era considerado nem lícito, nem ilícito, era encarado dentro de uma relação do homem com o mundo; implicava considerar o temperamento e o clima, as qualidades do corpo, as estações do ano, podendo ser prejudicial se não obedecesse a certa economia que variava de acordo com essa série de considerações. Levava em conta o problema de ser mais ou menos oportuno e conveniente. O mesmo valia para o comer. O regime para a Antiguidade Clássica era uma categoria fundamental, por meio da qual se pensava a maneira de conduzir a própria existência; não sendo adjacência da

\footnotetext{
${ }_{138}$ Trabalho apresentado na mesa "A sexualidade nos umbrais: entre Política e Psicanálise” no II Simpósio Bienal SBPSP "Fronteiras da Psicanálise: a clínica em movimento" no dia 29 de agosto de 2020.

139 Membro efetivo e docente da SBPSP, Mestre em Psicologia pela PUC-SP, Diretora de Cultura e Comunidade da SBPSP, autora de vários livros.
} 
medicina ou mera aplicação. Ao contrário, acreditava-se que a medicina derivava da dietética.

Sócrates, por exemplo, segundo Foucault, considerava que um homem de bem devia saber e aprender o necessário sobre geometria, astronomia, aritmética e sobre cuidar da própria saúde.

Que cada um se observe a si próprio e anote que comida, que bebida, que exercício lhe convêm e de que maneira usá-los a fim de conservar a mais perfeita saúde. Se vos observardes desse modo, diz Sócrates a seus discípulos, dificilmente encontrareis um médico que possa discernir melhor que vós próprios o que é favorável a vossa saúde." (Foucault, 1984/2006, p. 98).

Já o cristianismo propunha uma dietética, uma prática do sexo e do viver, em forma de atividade. Regulava e delimitava temporalmente a atividade sexual, determinando o momento permitido ou proibido, lógica binária. Fixava uniformemente e generalizada para todos os homens, independente de variações sazonais e de características específicas, os dias corretos e permitidos ao prazer sexual, as formas e os dias úteis para os cuidados com o corpo e com a alimentação.

A mulher do século XIX, por exemplo, é vista como uma eterna doente. A suposta fragilidade física das mulheres era argumento contra sua profissionalização, contra a exposição das mulheres ao tumulto das ruas e à vida noturna, contra quase todos os esforços físicos, contra o abuso nos estudos, contra os excessos sexuais. A medicina da época apresentava as etapas da vida feminina como uma sucessão de crises temíveis, independente de qualquer patologia. Além da gravidez e do parto, a puberdade e a menopausa eram consideradas "provações perigosas" e as menstruações, "feridas dos ovários que abalam o equilíbrio nervoso". As estatísticas provam que as mulheres sofreram, no século XIX, uma morbidez e uma mortalidade superior às dos homens. Justo na época das guerras napoleônicas, quando a mortalidade masculina cresceu enormemente.

A opinião púbica e numerosos médicos incriminavam a fraqueza da 'natureza feminina', causa biológica eterna e universal a justificar um fatalismo insuperável. A mortalidade das meninas, a partir dos cinco anos, em todos os países ocidentais no período oitocentista, aumentou. As causas confundiam-se com as próprias "precauções" justificadas pela dita fragilidade feminina: uma vida menos sadia, alimentação insuficiente a pretexto de ser "mais leve" (a 
exclusão de carnes vermelhas na dieta das meninas era hábito corrente), falta de exercícios físicos e ar puro - as meninas viviam trancadas em casa - frequência baixíssima de banhos em nome do pudor (uma vez por mês depois do período menstrual) além de uma negligência maior nos cuidados maternos e uma acolhida pouco calorosa, desde o nascimento. (Kehl, 1998).

Não foi à toa que a histeria de conversão cresceu enormemente no período vitoriano. $\mathrm{O}$ discurso médico muito contribuiu para que mulheres expressassem seus sofrimentos por meio de sintomas e sinais que mimetizavam doenças físicas - afinal eram as eternas doentes - revelando algumas condições sociais e a subjetividade da época. (Gay, 1988-1990/2000; Rose,1983/1997).

\section{$1 b$ Mentalidade de dieta - relação entre a psicogênese infantil e a cultural}

É possível entender os sintomas - principalmente aqueles que caracterizam sobremaneira uma época - ou ao menos sua psicoplastia, como resultado do entrelaçamento dos níveis sociocultural, intrapsíquico e psicopatológico, indo além dos clássicos conceitos de neurose, perversão e psicose; problematizando a relação entre a psicogênese infantil e a cultural. (Herrmann, 2003; 2004).

Se antes a mulher era uma eterna doente, hoje ela é uma eterna gorda e feia - independente de seu peso e medidas - revelando que cuidados se confundem com agressões e que o corpo não cabe mais no corpo. O sentimento de inadequação acaba por restringir e diminuir a circulação no espaço social. As mulheres ainda são as maiores vítimas dessa estratégia de dominação por meio da desvalorização de seus corpos, embora, com o encolhimento da sociedade patriarcal observamos homens, cada vez mais, sofrendo com problemas ligados de autoimagem e insatisfação corporal.

Em nossos consultórios e no cotidiano é raro encontrar quem não se sinta inferiorizado pela aparência, revelando inúmeras e frustradas dietas, cirurgias plásticas frequentes e tratamentos mágicos de rejuvenescimento.

A mentalidade de dieta (Orbach, 1978) controla as formas dos corpos e impõe ideais sociais. Da mentalidade de dieta surge uma nova moralidade dietética, que promove culpa em comer. A transgressão desloca-se mais para o valor calórico do que para o campo sexual. Os psicanalistas Fábio Herrmann e 
Marion Minerbo, no artigo "Creme e castigo", publicado no livro Psicanálise fim de século (1998), mostram como os complexos morais migram da sexualidade para a dieta, da cama para a cozinha e para a mesa. O que antes se expressava em termos de moralidade sexual ressurge como moral dietética, conservando regras e normas características do discurso sobre a sexualidade.

A forma de encarar o corpo também se altera, o corpo passa a ser objeto de autocontemplação, está diante e não dentro de nós, revelando que o sujeito psíquico foi expulso do homem. Enxergamos o corpo da mesma maneira como vemos uma foto. $\mathrm{O}$ corpo é imagem no espelho. No que tange aos cuidados corporais, observamos uma progressiva semelhança entre o funcionamento do corpo e o da máquina. Contamos calorias, controlamos inputs e outputs, calculamos massa magra, gorda etc. Nos exercitamos sob a égide de parâmetros científicos para obtermos resultados.

Desconectados do ato de saciar a fome com o alimento saboroso de nossa escolha e com a quantidade que sentimos ser suficiente. Nossa sociedade desaprendeu a comer, teme comer ou nem mesmo se permite comer e investigar a própria alimentação. Mediados por informações diferentes, nos encontramos perdidos diante do controle produzido por intermediários como: ciência, meios de comunicação, propaganda, moda, indústria, família e escola. Geram perda de autonomia do homem em relação a sua alimentação, propagando ideais sobre a imagem e forma dos corpos e sujeitando-nos ao saber de outro.

Os tratamentos convencionais indicam a dieta para quem deseja perder peso e para quem sofre em função de inúmeros distúrbios e problemas alimentares. Visam à contenção dos sintomas e à construção do corpo idealizado. Tendem a reforçar a perda de autonomia, cerne dos problemas alimentares, já que reproduzem os mesmos meios e objetivos que fazem o paciente adoecer. E, muitas vezes, levam-no a um uso fóbico, religioso e rígido da alimentação, das rotinas e dos cuidados corporais, que, em última instância, leva a um tipo particular de claustro e colabora, muito, na epidemia da obesidade.

O que é típico da resposta traumática é que o método ou meio usado para sanar um problema é, em geral, igual ou semelhante àquilo que gerou o problema.

A mentalidade de dieta é causa e consequência da falta de autonomia alimentar. É produzida socialmente; está internalizada e regula as relações do homem com a comida e o corpo. Comemos de forma externalizada. O sujeito 
psíquico que foi expulso do homem expeliu também e, inclusive, sua capacidade de julgar coisas bastante triviais, como a escolha do alimento que se tem vontade de comer e que matará a fome com prazer. Perdemos nossa capacidade de saborear os alimentos, de saber a hora de parar de comer, de saber quando se tem fome, de escolher os alimentos por livre e espontânea vontade. Comer se tornou um ato desconectado dos sinais internos que deveriam regulá-lo.

Pretender enxergar relação natural entre homem, alimentação e corpo é pura utopia. É claro que não existe autonomia alimentar completa nem relação com o corpo que não seja mediada pela cultura. No entanto, pensar abordagem analítica que não repita nem reforce a alienação do homem em relação ao comer e ao corpo é um desafio para a clínica contemporânea. Ao interrogarmos a clínica psicanalítica percebemos que, em geral, a questão da autonomia alimentar não é abordada. Muitos analistas internalizaram a mentalidade de dieta e não dispõem de outros recursos para trabalhar com as queixas mais frequentes.

\section{Tratamento}

Parti de um problema que diz respeito à dificuldade que a clínica padrão e as interpretações simbólicas clássicas e, mesmo, as ligadas à experiência emocional têm em promover transformações na relação dos pacientes com sua própria alimentação e com sua imagem corporal, para realizar algumas experiências clínicas com resultados interessantes, relatados em minha dissertação de mestrado (Mennucci, 2007).

Considerei o campo da alimentação em dois eixos entrelaçados. O primeiro diz respeito a psicomecânica alimentar, envolve os sinais de fome e saciedade, a quantidade e os tipos de alimento, os horários de alimentação e a privação tanto de alimentos como de prazer em comer. A mentalidade de dieta aliena o homem e perverte os sinais. A fobia à gordura, as dietas e as modas alimentares passam a dominar a alimentação, alterando, muitas vezes de forma dramática, a relação do homem com a comida.

O segundo eixo é mais conhecido por nós, psicanalistas. Denominei-o de psicodinâmica alimentar, envolve as relações objetais, a história familiar e pessoal da alimentação, a sexualidade, as fantasias sobre gordura e magreza, as fobias, os tabus e as interdições alimentares, bem como os afetos e representações 
correlacionados à alimentação, quando trabalhamos numa perspectiva psicanalítica mais clássica.

Experimentei uma técnica ativa que pudesse auxiliar no resgate dos sinais vitais da alimentação. Técnica que preconiza comer somente quando se sente fome, parar de comer assim que a saciedade chegar e escolher os alimentos livremente. Apliquei esse dispositivo guiada por um pensamento clínico que me levava a optar ora por iniciar o tratamento pela técnica, ora por introduzi-la quando sentisse ser necessário. A opção por utilizar uma técnica psicanalítica esteve em conformidade com o conceito de função terapêutica da psicanálise, propriedade intrínseca ao método psicanalítico de ruptura de campo, desenvolvido na Teoria dos Campos (Herrmann. 2001), considerando conhecimento e cura como resultado inseparável do tratamento.

Mudanças e inovações técnicas alargam os limites clínicos de atuação do psicanalista. Obrigam-nos a uma reflexão sobre a relação entre teoria e clínica em psicanálise. Para tanto, utilizarei o conceito de Alta Teoria, de Herrmann, que segundo Taffarel (2005) não se inscreve na ordem de criar teorias mais verdadeiras ou mais universais, mas assemelha-se ao movimento de teorização que a Teoria dos Campos chama de prototeoria: um abandonar-se ao não saber que se abre ao outro (paciente e cultura) pela escuta analítica, colocando o conhecimento psicanalítico consagrado entre parênteses e propiciando a emergência de uma pequena teoria, particular. Segundo essa autora, a prototeoria é uma versão singular das teorias consagradas, que, ao ser elaborada em termos não muito psicanalíticos, mas mais ficcionais, evita a saturação e libera o analista de usá-las de forma restritiva, repetitiva e inibidora, conservando um poder criativo. Sem deixá-lo, no entanto, totalmente à deriva, funciona como um farol: ilumina o caminho, mas não prescreve rotas previamente conhecidas.

\footnotetext{
A Alta Teoria é uma reflexão de caráter epistemológico que busca encontrar e descrever um campo de conhecimento afeito à psicanálise. Ela se propõe a estar atrás ou antes da teoria, ver seu avesso com o objetivo de fazê-la perder seu efeito inibidor. (Taffarel, 2005, p. 424).
}

Considerei essa experiência clínica não só como um desafio aos limites da clínica padrão mas, principalmente, como uma resposta à crise que a psicanálise enfrenta e à necessidade de encontrarmos, por meio da Alta Teoria (Taffarel, 2005), novas formas eficazes de clínica psicanalítica. 


\section{Referências}

Foucault, M. (2006). História da sexualidade: o uso dos prazeres (Vol. 2), São Paulo: Graal, 2006. (Original publicado em 1984).

Gay, P. (2000). A experiência burguesa: da rainha Vitória a Freud, Vol. 2: A paixão terna. São Paulo: Companhia das Letras. (Original publicado em 19881990).

Herrmann, F. (2001). Introdução à teoria dos campos. São Paulo: Casa do Psicólogo.

Herrmann, F. (2003). Adição à adição. Apresentado em Jornada Promud, 1, 22 nov. 2003. (Trabalho não publicado).

Herrmann, F. (2004). Apesar dos pesares: uma breve contribuição ao estudo da obesidade. In Anais da II Jornada psicanalítica sobre transtornos alimentares (pp. 1-6). São Paulo: SBPSP. (Trabalho não publicado)

Herrmann, F. \& Minerbo, M. (1998). Creme e castigo: sobre a migração dos valores morais da sexualidade à comida. In I. Carone, Psicanálise fim século (pp. 19-36). São Paulo: Hacker.

Kehl, M. R. (1998). Deslocamentos do feminino. Rio de Janeiro: Imago.

Mennucci, L.E.S. (2007). No campo dos problemas alimentares: uma técnica de tratamento psicanalítica [Dissertação de mestrado]. São Paulo: Pontifícia Universidade Católica.

Orbach, S. (1978). Fat Is a Feminist Issue. New York, Paddington Press.

Rose, P. (1997). Vidas paralelas: cinco casamentos vitorianos. Rio de Janeiro, Record. (Original publicado em 1983).

Taffarel, M. (2005). A alta teoria: uma proposta para a recorrente questão da relação teoria-prática. In L.M.C.Barone et al., A psicanálise e a clínica extensa (pp. 417-425). São Paulo, Casa do Psicólogo. 